\title{
Smoking Products Suppress Type I IFN During SARS-Cov-2 Infection
}

\author{
Zhenni $\mathrm{Lu}^{1}$ \\ ${ }^{1}$ Department of Mathematics and Department of Biology, Rensselaer Polytechnic Institute; Troy, NY, U.S.A.
}

\begin{abstract}
Coronavirus disease 2019 (COVID-19) is a global pandemic caused by the severe acute respiratory syndrome Coronavirus 2 (SARS-CoV-2), which can lead to the development severe pneumonia. While some hospital data shows a positive correlation between smoking and severe pneumonia, more molecular-level mechanisms need to be determined. The previous study investigates the mechanism of the negative effect of smoking on anti-viral infection on Type I interferons (IFNs). Research has shown that Type I IFNs play an important role in defending against SARS-Cov-2. Here, we want to investigate smoking components' effects on SARS-CoV-2 at the molecular level in vitro and give some ideas on the correlation between smoking and syndrome.
\end{abstract}

\section{Introduction}

As of 5 March 2021, almost 165 million people have been diagnosed with COVID-19 and more than two million deaths have been reported globally. The majority of patients with COVID-19 have mild symptoms, however some suffer from more severe symptoms. This is a global pandemic with its high rate of contagious, high rate of mutation, and its potential to overwhelm the healthcare system. Smoking has been shown to decrease resistance to the virus and data shows that smoking could decrease the benefits of IFN therapy, a potential treatment for COVID-19[1]. The lack of information on cigarette smoking products' effect on COVID-19 raises concern.

Type I interferons (IFNs) are important for the host to defend against viruses. Type I IFNs could promote the apoptosis of virus-infected cells through inducing proapoptotic molecules, and act on uninfected cells by inducing interferon-stimulated genes (ISGs) and immune cells to promote the maturation, expansion, and effects functions of NK cells, T cells, and B. cells[2]. My research focuses on Type I IFNs acting on uninfected cells. Type I IFNs, specifically IFN $\alpha$ and IFN $\beta$, are the major factors to defense against Covid-19. It recognizes the virus using the immune sensor activity. IFN $\alpha$ and IFN $\beta$ interact with IFNAR, the receptor for interferon, then lead to activation of kinases Tyk 2 and Jak 1 which then initiate tyrosine phosphorylation of Stat 1 and Stat2. Finally, Type I IFNs activates interferon-stimulated genes (ISG)whose products prevent viral replication and translation of viral proteins[3]. IFN plays an important role in antiviral response through innate recognition and immune evasion of the virus.

Coronaviruses, however, can interfere with IFN production and IFN signaling which are processes of innating antiviral immunity. First, SARS-CoV inhibits IFN-I. The membrane (M) protein, nucleocapsid(N) protein, and nsp3 of SARS-CoV will block the nuclear translocation of IRF3's, which is the transcription factor of IFN genes[4-6]. Second, viral proteins block IFNAR signaling. Nsp1 of SARS-CoV will inhibit the phosphorating of Stat1, which is the transcription factor of ISGs.

Studies have shown that the timing of IFN-I induction plays an essential role in viral replication which determines the response outcome. One study shows that 'early IFN- $\beta$ treatment before the viral peak was protective, whereas late treatment resulted in increased inflammation and lethal pneumonia[7].'Early triggering of Type I IFNs will help virus clearance and confer protection. On the other hand, avoiding and delaying triggering type I IFNs are associated with the severity COVID-19[8].

Moreover, data collected from COVID-19 patients presents that smoking is related with increased severity of infection. The previous study has shown cigarette smoking products stimulate the serine phosphorylationdependent ubiquitination which degrades the IFNAR subunit, the receptor of IFN $\alpha$ and IFN $\beta$, thus attenuating the IFN signaling[9].

In my current study, I want to investigate the effect of cigarettes on COVID-19 immune response. We will first investigate the effectiveness of the experiment design by pre-treating cells with serine/threonine-protein kinase D2 (PKD2) and MAP3K8. PKD2 could be used to mediate the phosphorylation of IFNAR1. Such phosphorylation will further promote the ubiquitatian and degradation of IFNAR1. Thus, Stat1 cannot be phosphorylated by IFNAR1[10]. MAP3K8 is a kinase inhibiting IRF3, a transcription factor for IFN genes, dimer formation. Thus, MAP3K8 would indirectly prevent the formation of IFN $\alpha$

luzhenni1230@gmail.com 
$\&$ IFN $\beta[11]$. Consequently, cell cultures pre-treated with PKD2 and MAP3K8 can affect cell anti-viral defense after infection by SARS-Cov-2.

Smokers are mimicked by cells injected with cigarette smoke condensate extract experience (CSCE). The CSCE level of a daily smoker is normally higher than $10 \mathrm{ng} / \mathrm{mL}$ and can even be as high as $500 \mathrm{ng} / \mathrm{ml}$. The average is between 30 and $50 \mathrm{ng} / \mathrm{ml}[12]$. Thus a low level of CSCE $(0.04 \%)$ would represent the nicotine intake of light smokers, a medium level of CSCE $(0.08 \%)$ would represent the nicotine intake of average smokers and a high level of CSCE $(0.12 \%)$ would represent the nicotine intake of heavy smokers. Cells treated with CSCE is used as treatment group.

Since COVID-19 a new disease, thus it is quite difficult to find a strict positive control group. A recent study shows the possibility of using Dexamethasone as a treatment for COVID-19 infection[13]. Dexamethasone could induce Type I tIFNs, increase the production of IFN $\alpha$ and IFN $\beta[14]$. However, whether it will early increase production of IFN $\alpha$ and IFN $\beta$ remains unknown. Cells treated with Dexamethasone showed an increase in Stat1 phosphorylation[15]. Thus, a group treated with Dexamethasone is used as a positive control; it is not a strictly positive control group though.

Question: Are smokers more likely to experience several SARS-Cov-2 infections? Are smokers more likely to experience a decrease in innate immune response, attenuation of IFN signaling, and delay in IFN response?

Hypothesis: Cell cultures treated with Dexamethasone display a virus load decrease compared with cells treated with Dimethyl sulfoxide (DMSO), increasing production of IFN $\alpha /$ IFN $\beta$ and stronger $p$-Stat 1 band. On the other hand, Cells pre-treated with increasing amounts of CSCE delay appearance of IFN-alpha and IFN-beta with COVID infection, weaker P-Stat1 band from the western blot, and higher viral load compared to cells treated with DMSO.

\section{Materials and Method}

1)Reagents: CSCE dissolved in DMSO to yield a $4 \%$ solution $(\mathrm{w} / \mathrm{v})$ and stored at $-80^{\circ} \mathrm{C}$. Nicotine and $\mathrm{N}$ acetyl-L-cysteine (NAC)[9].

2)Cell lines: Vero E6 or huh 7.

3)Control experiment: Negative control: Cells pretreated with DMSO for $2 \mathrm{~h}$. Positive control: Cells treated with Dexamethasone. Technique control group: cells were pre-treated with serine/threonine protein kinase D2 (PKD2) and MAP3K8.

After 0, 2,5,7,10,14, 20 days posted for SARS-Cov-2 infection to mimic the infection of SARS-Cov-2. Test IFN-alpha/IFN-beta, Stat1, P-Stat1, virus titre.

4)IFN response time: IFN-alpha, IFN-beta - using Enzyme-Linked Immunosorbent Assays (ELISA). 5)IFN signaling: Stat1 \& P-Stat1 With Licor western blot fluorescent antibodies. Severity: virus titre (pfu/ml) use COVID-19 ELISA IgG Antibody

\begin{tabular}{|l|l|}
\hline \multicolumn{1}{|c|}{ Table1. } & \multicolumn{1}{l}{ Cell line } \\
\hline Cell line & tissue \\
\hline Vero E6 & kidney \\
\hline Huh 7 & Liver tumor \\
\hline
\end{tabular}

\section{Possible results}

Positive control group: Table 2; Negative control group: Table 3; Possible results of treatment group: Table 4; Technique control group: Table 5.

Result 1: Positive control group: Virus load decrease compared with cells treated with DMSO. Increased production of IFN $\alpha /$ IFN $\beta$ and stronger $p-$ Stat1 band.

Treatment group: Virus load, IFN $\alpha / \operatorname{IFN} \beta$ \& p-Stat1 band strength do not change compared with cells treated with DMSO. Virus load goes down to 0 after 14 days.

Technique control group: No production of IFN $\alpha /$ IFN $\beta$, P-STAT1 band and virus load keep increasing

Result 2: Positive control group: Virus load decrease compared with cells treated with DMSO. Increase production of IFN $\alpha / \mathrm{IFN} \beta$ and stronger $\mathrm{p}$-Stat1 band.

Treatment group: Virus load and IFN $\alpha / \operatorname{IFN} \beta$ do not change compared with cells treated with DMSO. P-Stat1 band strength decreased compared with negative control group. Virus load goes down to 0 after 14 days.

Technique control group: No production of IFN $\alpha /$ IFN $\beta$, P-STAT1 band and virus load keep increasing

Result 3: Positive control group: Virus load decrease compared with cells treated with DMSO. Increase production of IFN $\alpha / \mathrm{IFN} \beta$ and stronger p-Stat1 band.

Technique control group: No production of IFN $\alpha /$ IFN $\beta$, P-STAT1 band and virus load keep increasing

Treatment group: Virus load increase and delay increase of IFN $\alpha /$ IFN $\beta$ compared with cells treated with DMSO. P-Stat1 band strength decreased compared with negative control group. Virus load goes down to 0 after 14 days.

Result 4: Positive control group: Virus load decrease compared with cells treated with DMSO. Increase production of IFN $\alpha /$ IFN $\beta$ and stronger $p$-Stat1 band.

Treatment group: Virus load increase and delay increase of IFN $\alpha /$ IFN $\beta$ compared with cells treated with DMSO. P-Stat1 band strength decreased compared with negative control group. Virus load does not go down to 0 after 14 days.

Technique control group: No production of IFN $\alpha /$ IFN $\beta$, P-STAT1 band and virus load keep increasing

Result 5: Positive control group: Virus load decrease compared with cells treated with DMSO. Increase production of IFN $\alpha /$ IFN $\beta$ and stronger $p$-Stat1 band.

Treatment group: Virus load decrease and early increase of IFN $\alpha /$ IFN $\beta$ compared with cells treated with DMSO. P-Stat1 band strength decreased compared with negative control group. Virus load goes down to 0 after 14 days.

Technique control group: No production of IFN $\alpha /$ IFN $\beta$, P-STAT 1 band and virus load keep increasing

Result 6: Positive control group: Virus load decrease compared with cells treated with DMSO. Increase production of IFN $\alpha /$ IFN $\beta$ and stronger $p$-Stat1 band. 
Treatment group: Virus load decrease and early increase of IFN $\alpha /$ IFN $\beta$ compared with cells treated with DMSO. P-Stat1 band strength has little change compared with negative control group. Virus load goes down to 0 after 14 days.

Technique control group: No production of IFN $\alpha /$ IFN $\beta$, P-STAT1 band and virus load keep increasing

Table2. Possible results of Positive control group

\begin{tabular}{|c|c|c|c|c|c|c|c|}
\hline & Result 1 & Result 2 & Result 3 & Result 4 & Result 5 & Result 6 & Result 7 \\
\hline virus load & - & - & - & - & - & - & 0 \\
\hline $\begin{array}{l}\text { Virus load goes down } \\
\text { to } 0 \text { at day } 20 \text { ? }\end{array}$ & yes & yes & yes & yes & yes & yes & No \\
\hline IFN $\alpha /$ IFN $\beta$ & + & + & + & + & + & + & 0 \\
\hline $\begin{array}{l}\text { p-STAT1 band } \\
\text { strength }\end{array}$ & + & + & + & + & + & + & 0 \\
\hline $\begin{array}{l}\text { Associated with } \\
\text { hypothesis? }\end{array}$ & yes & yes & yes & yes & yes & yes & No \\
\hline IFN $\alpha / \operatorname{IFN} \beta$ & + & + & + & + & & & \\
\hline $\begin{array}{l}\text { p-STAT1 band } \\
\text { strength }\end{array}$ & + & + & + & + & & & \\
\hline $\begin{array}{l}\text { Associated with } \\
\text { hypothesis? }\end{array}$ & yes & yes & yes & yes & & & \\
\hline
\end{tabular}

'+' represents increase, '-' represents decrease, '0'represents unchanged

Table3. Possible results of Negative control group - Used as standard

\begin{tabular}{|l|l|l|l|l|l|l|l|}
\hline & Result 1 & Result 2 & Result 3 & Result 4 & Result 5 & Result 6 & Result 7 \\
\hline virus load & 0 & 0 & 0 & 0 & 0 & 0 & 0 \\
\hline Virus load goes down to 0 at day 20? & Yes & Yes & Yes & Yes & Yes & Yes & No \\
\hline IFN $\alpha /$ IFN $\beta$ & 0 & 0 & 0 & 0 & 0 & 0 & 0 \\
\hline p-STAT1 band & 0 & 0 & 0 & 0 & 0 & 0 & 0 \\
\hline Associated with hypothesis? & yes & yes & yes & yes & yes & yes & No \\
\hline
\end{tabular}

'+' represents increase, '-' represents decrease, '0' represents unchanged

Table4. Possible results of treatment group: increasing amount of CSCE

\begin{tabular}{|l|l|l|l|l|l|l|l|}
\hline & Result 1 & Result 2 & Result 3 & Result 4 & Result 5 & Result 6 & Result 7 \\
\hline virus load & 0 & 0 & + & + & - & - & 0 \\
\hline Virus load goes down to 0 at day 20? & Yes & yes & yes & No & yes & yes & No \\
\hline IFN /IFN $\beta$ & 0 & 0 & ++ & ++ & -- & -- & 0 \\
\hline p-STAT1 band strengs & 0 & - & - & - & - & 0 & 0 \\
\hline Associated with hypothesis? & no & no & yes & yes & no & no & No \\
\hline
\end{tabular}

'+' represents increase, '-' represents decrease, ' 0 ' represents unchanged

'++'represents delay, '--' represents early, '0' represents unchanged

Table5. Possible results of technique control group

\begin{tabular}{|l|l|l|l|l|l|l|l|}
\hline & Result 1 & Result 2 & Result 3 & Result 4 & Result 5 & Result 6 & Result 7 \\
\hline virus load & + & + & + & + & + & + & + \\
\hline $\begin{array}{l}\text { Virus load goes down to 0 at } \\
\text { day 20? }\end{array}$ & No & No & No & No & No & No & No \\
\hline IFN /IFN $\beta$ & $\begin{array}{l}\text { Not } \\
\text { showing }\end{array}$ & $\begin{array}{l}\text { Not } \\
\text { showing }\end{array}$ & $\begin{array}{l}\text { Not } \\
\text { showing }\end{array}$ & $\begin{array}{l}\text { Not } \\
\text { showing }\end{array}$ & $\begin{array}{l}\text { Not } \\
\text { showing }\end{array}$ & $\begin{array}{l}\text { Not } \\
\text { showing }\end{array}$ & $\begin{array}{l}\text { Not } \\
\text { showing }\end{array}$ \\
\hline p-STAT1 band strength & $\begin{array}{l}\text { Not } \\
\text { showing }\end{array}$ & $\begin{array}{l}\text { Not } \\
\text { showing }\end{array}$ & $\begin{array}{l}\text { Not } \\
\text { showing }\end{array}$ & $\begin{array}{l}\text { Not } \\
\text { showing }\end{array}$ & $\begin{array}{l}\text { Not } \\
\text { showing }\end{array}$ & $\begin{array}{l}\text { Not } \\
\text { showing }\end{array}$ & $\begin{array}{l}\text { Not } \\
\text { showing }\end{array}$ \\
\hline Associated with hypothesis? & yes & yes & yes & yes & yes & yes & yes \\
\hline
\end{tabular}

\footnotetext{
'+' represents increase
} 


\section{Discussion}

If the experiment is successfully designed, we would observe no IFN $\alpha$ and IFN $\beta$ present and no band for PStat 1 while showing IFN $\alpha$ and IFN $\beta$ and bands for P-stat 1 .

Consistent with this assumption of no error in experiment design, pre-treatment of cells with CSCE decreased type I IFNs, shown as delay increasing of IFN $\alpha$ and IFN $\beta$, decreasing level of P-stat 1 and increasing virus load. Pre-treatment of cells with low, medium and high levels of CSCE would show different levels of decreasing effect type I IFN. Virus load is related to severity of Coivd-19 infection.

Results 1 and 2 do not correlate with the hypothesis. Both show that smoking has no significant effects on increasing virus load, which is correlated with the severity of COVID-infection. In Result 2, the P-Stat1 band is becoming weaker compared with the negative control group, which corresponds with the previous study of CSCE, this would stimulate the serine phosphorylationdependent degradation of IFNAR1[9]. This shows that smoking would only weaken IFN signaling.

Results 3 and 4 are consistent with the hypothesis and the study of CSCE. Thus, we observe a weaker p-Stat1 band compared with the negative control group. These could reflect that smoker would be more likely to experience a delay in Type I IFN, and more severe SARSCov-2 infection compared with non-smokers. Unlike in Result 4, virus load goes down to 0 after 14 days in Result 3 , this shows that smokers may not have a high risk of experiencing tissue damage and even death. This shows that smoking has a so strong suppressing effect on IFN that virus is out of control. Thus, smoking has a high probability of relating to the lethal syndrome.

Results 5 and 6 do not agree with the hypothesis. We would expect a delay increase of IFN $\alpha /$ IFN $\beta$ but Results 5 and 6 display the opposite. This may be because SARsCov-2 - having a special protein, a gene coding sequence, or a surface receptor that would interact with CSCE—and its function would be reduced by CSCE.

The failure of the in vivo experiment described in Result 7 (figure 1) may most likely caused by the experiment failure. Vero E6 or huh 7 in vivo may die before the experiment or CSCE may be contaminated which kills the cells, thus in the negative control group virus load does not go down.

\section{Conclusion}

Type I IFNs contributes an important role against SARSCov-2 infection. This study wants to explore smoking products' effects on SARS-Cov-2 infection and further try to illustrate whether smokers will be more likely to undergo a more severe infection in vitro. Further studies are required to investigate if CSCE can suppress Type I IFNs in vivo.

The mechanism of IFN-I signaling is not fully understood, future study could focus on identifying host factors that cause delayed IFN-I induction[16].
In results 3 and 4 we observe a delay increasing of IFN $\alpha /$ IFN $\beta$, while the mechanism for such delay is unknown. In results 5 and 6 we observe an early increase of IFN $\alpha /$ IFN $\beta$. This provides us a new possibility that CSCE may be used as a treatment for COVID-19. The mechanism for such phenomena needs further investigation.

Some studies present that nicotine also regulates angiotensin-converting enzyme 2 (ACE2), which SARSCoV-2 is known to use as a receptor for cell entry[17]. However, studies on smoking show contradictory effects on ACE2. Studies published before the COVID-19 pandemic reported that smoking and nicotine would suppress the expression ACE2[18].Thus, further study may need to consider ACE2 effects on SARS-Cov-2 infection

\section{References}

1. El-Zayadi, A., et al., Impact of cigarette smoking on response to interferon therapy in chronic hepatitis $\mathrm{C}$ Egyptian patients. World J Gastroenterol, 2004. 10(20): p. 2963-6.

2. McNab, F., et al., Type I interferons in infectious disease. Nat Rev Immunol, 2015. 15(2): p. 87-103.

3. Pestka, S., C.D. Krause, and M.R. Walter, Interferons, interferon-like cytokines, and their receptors. Immunol Rev, 2004. 202: p. 8-32.

4. Devaraj, S.G., et al., Regulation of IRF-3-dependent innate immunity by the papain-like protease domain of the severe acute respiratory syndrome coronavirus. J Biol Chem, 2007. 282(44): p. 32208-21.

5. Kopecky-Bromberg, S.A., et al., Severe acute respiratory syndrome coronavirus open reading frame (ORF) 3b, ORF 6, and nucleocapsid proteins function as interferon antagonists. J Virol, 2007. 81(2): p. 548-57.

6. Yang, Y., et al., The structural and accessory proteins M, ORF 4a, ORF 4b, and ORF 5 of Middle East respiratory syndrome coronavirus (MERS-CoV) are potent interferon antagonists. Protein Cell, 2013. 4(12): p. 951-61.

7. Channappanavar, R., et al., IFN-I response timing relative to virus replication determines MERS coronavirus infection outcomes. J Clin Invest, 2019. 129(9): p. 3625-3639.

8. Blanco-Melo, D., et al., Imbalanced Host Response to SARS-CoV-2 Drives Development of COVID-19. Cell, 2020. 181(5): p. 1036-1045.e9.

9. HuangFu, W.C., et al., Cigarette smoking products suppress anti-viral effects of Type I interferon via phosphorylation-dependent downregulation of its receptor. FEBS Lett, 2008. 582(21-22): p. 3206-10.

10. Zheng, H., et al., Tyrosine phosphorylation of protein kinase D2 mediates ligand-inducible elimination of the Type 1 interferon receptor. J Biol Chem, 2011. 286(41): p. 35733-35741.

11. Yao, Y., et al., Neutralization of interferonalpha/beta-inducible genes and downstream effect in 
a phase I trial of an anti-interferon-alpha monoclonal antibody in systemic lupus erythematosus. Arthritis Rheum, 2009. 60(6): p. 1785-96.

12. Benowitz, N.L., J. Hukkanen, and P. Jacob, 3rd, Nicotine chemistry, metabolism, kinetics and biomarkers. Handb Exp Pharmacol, 2009(192): p. 29-60.

13. Lammers, T., et al., Dexamethasone nanomedicines for COVID-19. Nat Nanotechnol, 2020. 15(8): p. 622-624.

14. Soury, B., et al., Induction of interferon-beta gene expression by dexamethasone in murine L929 cells. Mol Endocrinol, 1995. 9(2): p. 199-207.

15. Feng, Z., et al., Fludarabine inhibits STAT1-mediated up-regulation of caspase-3 expression in dexamethasone-induced osteoblasts apoptosis and slows the progression of steroid-induced avascular necrosis of the femoral head in rats. Apoptosis, 2017. 22(8): p. 1001-1012.

16. Park, A. and A. Iwasaki, Type I and Type III Interferons - Induction, Signaling, Evasion, and Application to Combat COVID-19. Cell Host Microbe, 2020. 27(6): p. 870-878.

17. Zhang, H., et al., Angiotensin-converting enzyme 2 (ACE2) as a SARS-CoV-2 receptor: molecular mechanisms and potential therapeutic target. Intensive Care Med, 2020. 46(4): p. 586-590.

18. Oakes, J.M., et al., Nicotine and the renin-angiotensin system. Am J Physiol Regul Integr Comp Physiol, 2018. 315(5): p. R895-r906. 